\title{
Post-stroke sleep disorders in Egyptian patients by using simply administered questionnaires: a study from Ain Shams University
}

\author{
Alia H. Mansour ${ }^{1 *}$ (D, Maged Ayad ${ }^{2}$, Naglaa El-Khayat ${ }^{1}$, Ahmed El Sadek ${ }^{1}$ and Taha K. Alloush ${ }^{1}$
}

\begin{abstract}
Introduction: Stroke is a leading cause of disability worldwide with grave morbidity and mortality. Sleep and stroke have a definite intermingling neuropathological relationship, so along with expeditious acute management, efficient secondary prevention and consistent rehabilitation, sleep disorders' management has a hand in offering a medical service up to the mark.

Objective: Screening of sleep disorders' prevalence in patients who survived a previous stroke by applying simple questionnaires and to determine the correlation between these disorders and stroke's demographic, clinical, and risk factor variables.

Methods: Cross-sectional prospective study on 75 stroke patients from stroke outpatient clinic and all patients were subjected to answer a sheet of sleep questionnaire, Pittsburg Sleep Quality Index (PSQI), Epworth Sleepiness Scale (ESS), and Apnea/Hypopnea Index (AHI), Arabic versions. Results

A total of $70.6 \%$ were found to have sleep disorders, $61.6 \%$ had poor sleep quality, 20\% had a severe degree of excessive day time sleepiness (EDS). Sleep disorders were more prevalent in the moderate severity of stroke by NIHSS and in the first 1-4 weeks. There was no correlation between the occurrence of sleep disorders and the site of the lesion.

Conclusion: Sleep disorders are broadly prevalent after a stroke. Resulting damage impedes the functional outcome. Simple questionnaires are easy applicable methods for screening of such disorders in post-stroke patients. Guidelines needed regarding screening and management of sleep disorders after a stroke.
\end{abstract}

Keywords: Stroke, Sleep, Post-stroke, Insomnia, Sleep-disordered breathing, EDS, Apnea

\section{Introduction}

Stroke is a leading cause of disability worldwide with grave morbidity and mortality [1]. It is the second cause of death in Egypt, after ischemic heart disease with a high prevalence of 963/100000 populations [2]. Along with expeditious acute management, efficient secondary prevention and consistent rehabilitation, sleep disorders' management has a hand in offering a medical service up to the mark.

\footnotetext{
* Correspondence: alia.hassan@med.asu.edu.eg

${ }^{1}$ Neurology Department, Faculty of Medicine, Ain Shams University, Ramsis

St., Abbassis Square, Cairo, Egypt

Full list of author information is available at the end of the article
}

Ain Shams University Hospital is a tertiary center for neurology and an accredited center for offering comprehensive stroke services in the region through our stroke unit and stroke outpatient clinic.

Sleep disorders are growingly recognized as a salient consideration while management of different neurological diseases and stroke specifically [3-6], though its weightiness, only about $6 \%$ of stroke survivors are offered formal sleep testing and an estimated $2 \%$ complete such testing in the 3-month post-stroke period. That may be ought to uncertain timing for proper sleep testing after a stroke [7], added to inadequate awareness about sleep disorders and 
implication on stroke's outcome and overwhelming with vascular treatment.

From practical point of view, sleep disorders sometimes may be in the dark side of the tunnel, some physicians are reluctant about navigating this area in the history, especially if it did not come to patient's attention as restless leg syndrome, periodic leg movement, parasomnia, as those antecedent disorders in the context of surviving stroke patient are usually forgotten, to the contrary of insomnia, or excessive day time sleepiness; however, the later may be misinterpreted as fatigue or sleepiness from a stroke.

So, this study was done to improve awareness about post-stroke sleep disorders among physicians and healthcare practitioners dealing with stroke patients.

\section{Aim of the work}

Description of prevalence of sleep disorders in patients who survived stroke and the severity and magnitude of these disorders and to study the correlation between sleep disorders post-stroke and stroke demographic, clinical and risk factor variables, and to spotlight an easy approach for post-stroke sleep screening.

\section{Subjects and methods}

This is a cross-sectional prospective study, 75 patients were selected from the attendees of stroke outpatient clinic at Ain Shams University Hospital from January 2015 to December 2015. Their routine investigational data were recorded (magnetic resonance image on the brain (MRI), magnetic resonance angiography for brain (MRA), electrocardiography (ECG), echocardiography, vertebrobasilar and carotid duplex, hemoglobin A1c (HbA1c) level, lipid profile: cholesterol $(\mathrm{CH})$, triglycerides (TGs) and low-density lipoprotein (LDL).

Patients were subjected to full neurological history and examination, structured sheet of sleep questionnaire, and were interviewed by the following questionnaires: structured sheet for sleep questionnaire [7], Pittsburg Sleep Quality Index (PSQI) [8], Epworth sleepiness scale (ESS)
[9], Apnea/Hypopnea Index (AHI) Arabic version Additional file 1 [7].

Inclusion criteria of the patients were as followed:

1- First-ever stroke either ischemic or hemorrhagic.

2- The interval between the onset of stroke symptoms and the date of the interview does not exceed 12 weeks (3 months).

3- Age range between 18 years and 70 years old.

Exclusion criteria were:

1- Subarachnoid hemorrhage and cerebral sinus thrombosis.

2- Primary sleep disorders prior to stroke onset.

3- Patients who had end-stage medical illness and those with a neurological disease or a psychiatric disorder known to affect sleep. In addition, patients who were on medications reputed to affect sleep physiology.

\section{Statistical analysis}

Data were analyzed using SPSS version 20. Qualitative data were presented as numbers and percentages. Chisquare test and/or Fisher exact test were used for qualitative data which was used instead of chi-square test when the expected count in any cell was found less than 5 . The confidence interval was set to $95 \%$ and the margin of error accepted was set to $5 \%$. $P$ value was considered significant as the following: $P>0.05$ : non-significant, $P<0.05$ : significant, $P<0.01$ : highly significant.

\section{Results}

Our sample included 75 patients with 34 (45.3\%) males and 41 ( 54.7\%) females, mean age \pm standard deviation (SD) $59.3 \pm 5.34,70.6 \%$ were shown to have sleep disorders, the details are shown in Table 1; in addition, Fig. 1 showed different sleep phenomena accounted for in our patients.

The detailed data by applying the nominated sleep questionnaires revealed that $17.3 \%$ suffered from severe

Table 1 Sleep disorders and phenomenon after stroke

\begin{tabular}{llll}
\hline Sleep disorders & & No. & \multicolumn{1}{c}{ Percent } \\
\hline No complaints & & 9 & $12.0 \%$ \\
Insomnia & Initial insomnia & $3.7 \%$ \\
& Middle insomnia & $3.0 \%$ & 13 \\
Excessive daytime sleepiness (EDS) & & 7 & $5.3 \%$ \\
Parasomnia and normal behavioral phenomenon & Nightmares & 5 & $6.7 \%$ \\
& Arousal confusion & 5 & $6.7 \%$ \\
& Sleep talking & 3 & $4.0 \%$ \\
Sleep-disordered breathing (SDB) & Sleep paralysis & 22 & $29.3 \%$ \\
Total & & 75 & 100.0 \\
\hline
\end{tabular}




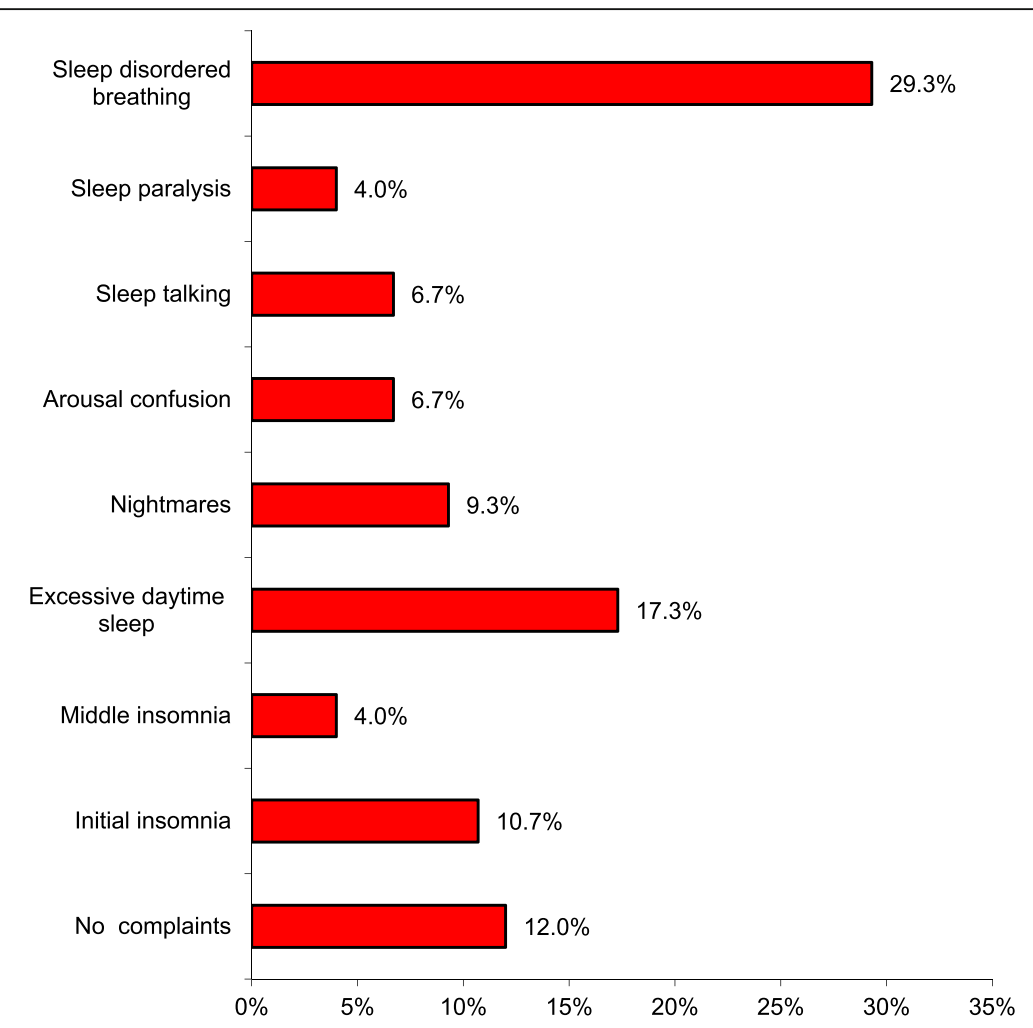

Fig. 1 Distribution of sleep phenomenon and complaints in our patients' sample, with SDB being the highest and EDS came second in the rank, while middle sleep insomnia accounted for the least percentage

EDT, i.e., score more than 16, coming to sleepdisordered breathing 14 (18.7\%) patients had a moderate form of apnea while $8(10.6 \%)$ patients suffered from a severe degree of apnea. And on the whole, $61.3 \%$ were poor sleepers, i.e., score more than 5 in the Pittsburg sleep scale [8] (Table 2).

Upon correlation between different sleep disorders and stroke risk factors, it was found that non-cardiac patients have more prevalence of different sleep disorders; however, this was not statistically different from cardiac patients (Table 3).

Sleep complaints were more common in moderate stroke according to the NIHSS scale (very severe $>25$, severe $15-24$, mild to moderately severe $5-14$, mild $1-5$

Table 2 Data of the applied questionnaires

\begin{tabular}{llll}
\hline & & No. & Percent \\
\hline Pittsburg sleep quality index (PSQI) & Equal or less than 5 & 29 & $38.7 \%$ \\
& More than 5 & 46 & $61.3 \%$ \\
Epworth sleepiness scale (ESS) & Equal or less than 16 & 60 & $80.0 \%$ \\
& More than 16 & 15 & $20.0 \%$ \\
Apnea/Hypopnea Index (AHI) & $0-2$ & 53 & $70.7 \%$ \\
& $3-8$ & 14 & $18.7 \%$ \\
& $9,10,12-14$ & 8 & $10.6 \%$ \\
\hline
\end{tabular}

) [10], however, with no statistical significance. Moreover, it is higher during the first 4 weeks after stroke but with no statistical difference as well. In the first few weeks after stroke, the patient is exposed to this new stressor that has provoked the occurrence of the nominated disorders (Table 4).

Figure 2 Demonstrates the relationship between stroke site and different sleep disorders.

\section{Discussion}

Sleep is a complex process that involves many areas in the brain including the pedunculopontine nucleus (PPD), lateral dorsal tegmentum (LDT), locus coeruleus (LC), preoptic area, posterior hypothalamus, and a flip flop switch in a harmonious manner. Moreover, many neurotransmitters are involved in this process [11]. So, any condition that leads to disruption of the aforementioned components would affect sleep, this includes many neurological disorders, and far and away stroke comes in the center.

Though sleep disorders are widely prevalent and markedly transform the quality of life status of patients, they are usually a forsaken category by physicians while managing a stroke patient, whether acutely or during secondary prevention plan. There are no clear guidelines on how to deal with these disorders after a stroke or 
Table 3 Statistical correlations between sleep disorders after stroke and stroke risk factors

\begin{tabular}{|c|c|c|c|c|c|c|c|c|c|c|c|c|c|}
\hline & & \multicolumn{2}{|c|}{$\begin{array}{l}\text { Excessive daytime } \\
\text { sleepiness }\end{array}$} & \multicolumn{2}{|c|}{ Insomnia } & \multicolumn{2}{|c|}{$\begin{array}{l}\text { No } \\
\text { complaints }\end{array}$} & \multicolumn{2}{|c|}{ Parasomnia } & \multicolumn{2}{|c|}{$\begin{array}{l}\text { Sleep-disordered } \\
\text { breathing }\end{array}$} & \multicolumn{2}{|c|}{$\begin{array}{l}\text { Chi-square } \\
\text { test }\end{array}$} \\
\hline & & No. & $\%$ & No. & $\%$ & No. & $\%$ & No. & $\%$ & No. & $\%$ & $\overline{X^{2}}$ & $P$ value \\
\hline \multirow[t]{2}{*}{ Hypertension } & No & 0 & $0.0 \%$ & 1 & $9.1 \%$ & 1 & $11.1 \%$ & 1 & $5.0 \%$ & 3 & $13.6 \%$ & 2.461 & 0.652 \\
\hline & Yes & 13 & $100.0 \%$ & 10 & $90.9 \%$ & 8 & $88.9 \%$ & 19 & $95.0 \%$ & 19 & $86.4 \%$ & & \\
\hline \multirow[t]{3}{*}{ Diabetes mellitus (DM) } & $\mathrm{HbA} 1 \mathrm{c}<7$ & 2 & $15.4 \%$ & 5 & $45.5 \%$ & 4 & $44.4 \%$ & 10 & $50.0 \%$ & 12 & $54.5 \%$ & 7.403 & 0.494 \\
\hline & $\mathrm{HbA1c}>7$ & 4 & $30.8 \%$ & 1 & $9.1 \%$ & 2 & $22.2 \%$ & 2 & $10.0 \%$ & 4 & $18.2 \%$ & & \\
\hline & No & 7 & $53.8 \%$ & 5 & $45.5 \%$ & 3 & $33.3 \%$ & 8 & $40.0 \%$ & 6 & $27.3 \%$ & & \\
\hline \multirow[t]{2}{*}{ Heart disease } & No & 10 & $76.9 \%$ & 10 & $90.9 \%$ & 6 & $66.7 \%$ & 18 & $90.0 \%$ & 18 & $81.8 \%$ & 3.190 & 0.526 \\
\hline & Yes & 3 & $23.1 \%$ & 1 & $9.1 \%$ & 3 & $33.3 \%$ & 2 & $10.0 \%$ & 4 & $18.2 \%$ & & \\
\hline \multirow[t]{2}{*}{ Smoking } & No & 7 & $53.8 \%$ & 7 & $63.6 \%$ & 4 & $44.4 \%$ & 10 & $50.0 \%$ & 9 & $40.9 \%$ & 1.720 & 0.787 \\
\hline & Yes & 6 & $46.2 \%$ & 4 & $36.4 \%$ & 5 & $55.6 \%$ & 10 & $50.0 \%$ & 13 & $59.1 \%$ & & \\
\hline
\end{tabular}

throughout the secondary prevention journey. In addition, that topic is not under spotlights in the regional and national stroke conferences and meetings.

This study used an easy applicable questionnaire, which is quick to perform, and thus constitute a tool that could be practically applied in everyday practice.

As mooted earlier, sleep and stroke have definite relationship, stroke affects sleep microstructures in different ways, different studies indicated an association between different stroke sites and or side of stroke and the affection of REM and non-REM sleep [12, 13]. Moreover, different markers as il-1, IL-6, and TNF- $\alpha$ that are incremented in a stroke had been found to result from sleep deprivation and insomnia [14-18]; hence, early detection of sleep disorders is mandatory to prevent further damage.

A respectable sector of stroke patients (20\%-63\%) manifests by different sleep disorders as hypersomnia, insomnia, parasomnias, circadian rhythm disorders, periodic limb movement disorder, and sleep-disordered breathing [19]. In our study, it was found that $70.6 \%$ had sleep disorders, auscultating raised points in this discussion, it is definitely an enormous issue.

Hence, sympathetic overactivity and reduced cerebral blood flow are the suggested mechanisms for the occurrence of some sleep disorders like insomnia, SDB [20], and periodic leg movements, as well as instigation of the development of stoke. Proper management of these disorders is mandatory for stroke secondary prevention and might unfold and clear up reasons behind recurrent strokes in optimally treated patients. In a recent study, earlier this year (the basic project) that used a survey on 842 patients with stroke in south Texas, SDB represented a modifiable factor associated with a higher rate of recurrent stroke and poor functional outcome [21].

SDB is more prevalent in stroke than non-stroke patients [22], in our study, $29.3 \%$ had possible SDB by the Apnea index questionnaire to be confirmed by polysomnography, different studies reported a prevalence rate range between 43 and 72\%, higher prevalence might be

Table 4 Statistical correlations between sleep disorders after stroke and stroke clinical variables

\begin{tabular}{|c|c|c|c|c|c|c|c|c|c|c|c|c|c|}
\hline & & \multicolumn{2}{|c|}{$\begin{array}{l}\text { Excessive daytime } \\
\text { sleeping }\end{array}$} & \multicolumn{2}{|c|}{ Insomnia } & \multicolumn{2}{|c|}{$\begin{array}{l}\text { No } \\
\text { complaints }\end{array}$} & \multicolumn{2}{|c|}{ Parasomnia } & \multicolumn{2}{|c|}{$\begin{array}{l}\text { Sleep-disordered } \\
\text { breathing }\end{array}$} & \multicolumn{2}{|c|}{ Chi-square test } \\
\hline & & No. & $\%$ & No. & $\%$ & No. & $\%$ & No. & $\%$ & No. & $\%$ & $x^{2}$ & $P$ value \\
\hline \multirow[t]{2}{*}{ Type } & Hemorrhagic & 6 & $46.2 \%$ & 4 & $36.36 \%$ & 5 & $55.6 \%$ & 7 & $35.0 \%$ & 9 & $40.91 \%$ & 1.320 & 0.857 \\
\hline & Ischemic & 7 & $53.8 \%$ & 7 & $36.64 \%$ & 4 & $44.4 \%$ & 13 & $65.0 \%$ & 13 & $59.09 \%$ & & \\
\hline \multirow[t]{3}{*}{ Side } & Left hemisphere & 6 & $46.15 \%$ & 5 & $45.45 \%$ & 6 & $66.7 \%$ & 9 & $45.0 \%$ & 7 & $31.82 \%$ & 4.843 & 0.774 \\
\hline & Right hemisphere & 4 & $30.77 \%$ & 3 & $27.27 \%$ & 3 & $33.3 \%$ & 6 & $30.0 \%$ & 8 & $36.36 \%$ & & \\
\hline & Brainstem & 3 & $23.08 \%$ & 3 & $27.27 \%$ & 0 & $0.0 \%$ & 5 & $25.0 \%$ & 7 & $31.82 \%$ & & \\
\hline \multirow[t]{3}{*}{ Severity (NIHSS) } & Minor & 5 & $38.5 \%$ & 5 & $45.5 \%$ & 5 & $55.6 \%$ & 9 & $45.0 \%$ & 16 & $72.7 \%$ & 14.243 & 0.076 \\
\hline & Moderate & 8 & $61.5 . \%$ & 5 & $45.5 \%$ & 4 & $44.4 .0 \%$ & 6 & $30.0 \%$ & 5 & $22.7 \%$ & & \\
\hline & Moderately severe & 0 & $0.0 \%$ & 1 & $9.1 \%$ & 0 & $0.0 \%$ & 5 & $25.0 \%$ & 1 & $4.5 \%$ & & \\
\hline \multirow[t]{3}{*}{ Time } & 1-4 weeks & 8 & $61.5 \%$ & 9 & $81.8 \%$ & 5 & $55.6 \%$ & 10 & $50.0 \%$ & 15 & $68.2 \%$ & 5.815 & 0.668 \\
\hline & 5-8 weeks & 5 & $38.5 \%$ & 2 & $18.2 \%$ & 4 & $44.4 \%$ & 9 & $45.0 \%$ & 7 & $31.8 \%$ & & \\
\hline & 9-12 weeks & 0 & $0.0 \%$ & 0 & $0.0 \%$ & 0 & $0.0 \%$ & 1 & $5.0 \%$ & 0 & $0.0 \%$ & & \\
\hline
\end{tabular}




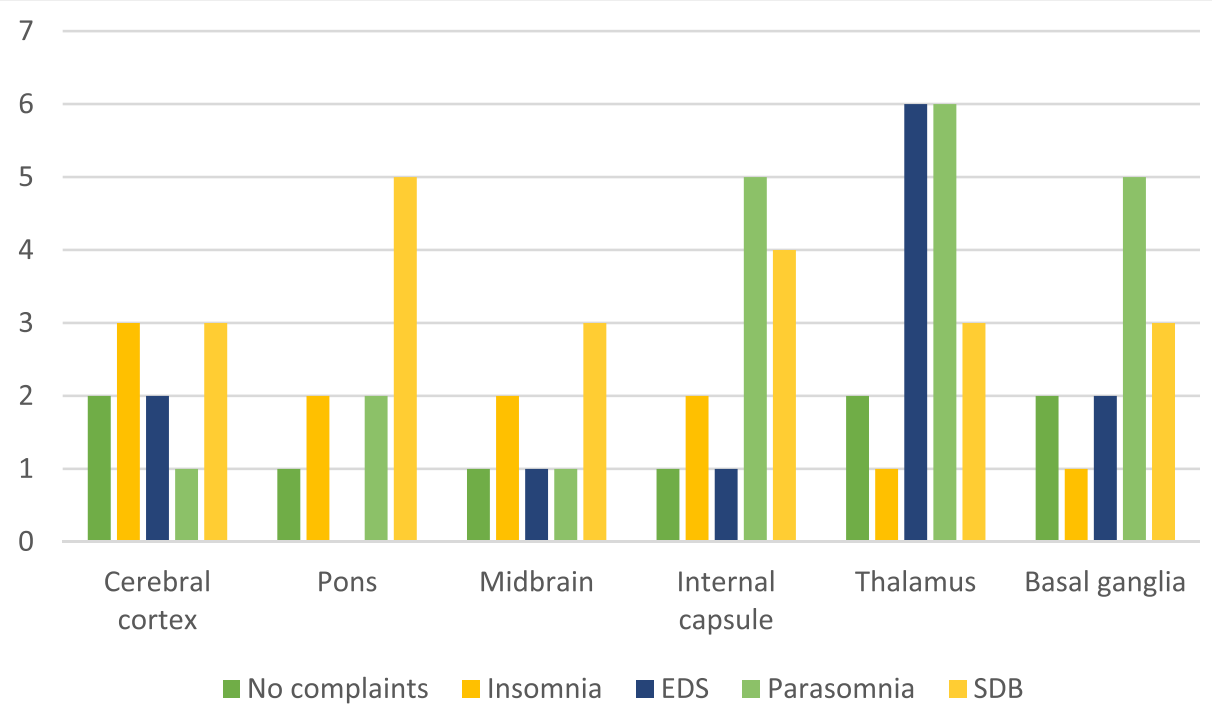

Fig. 2 Different sleep disorders and relation with the site of the lesion

attributed to preexisting SDB and not counting de novo cases only [23-25]. In a study done in Switzerland, better stroke outcome, and less morbidity and mortality was associated with a lower Apnea, and Apnea/Hypopnea Index [22]. Under recognition of SDB lead to high functional impairment in the long term.

Furthermore, in a systematic review about insomnia after stroke, it was found that insomnia prevalence ranges from $14 \%$ to $59 \%$ in studies used clinical diagnostic tools and $19.8 \%$ to $69 \%$ using non-clinical diagnostic tools and a variety of diagnostic questionnaires, and in that systematic review, one study reported association between cortical lesions and poor sleep quality [26], in our cross-sectional study insomnia prevalence was $14.7 \%$ with $10.7 \%$ had initial insomnia. Insomnia stands as independent risk factor for cerebrovascular reactivity (CVR) and aggravation of sympathetic hyperactivity [27], thus early detection and management is mandatory. Different factors enact in this as the external environment in the stroke unit (frequent medication, stress related to the recently developed illness, frequent medication), comorbid psychiatric disorders such as anxiety and depression, in addition to the effect of the inflammatory mediators released by the damaged tissue as mentioned earlier in this text.

This study has a limitation that polysomnography was not done to confirm the presence of different as sleepdisordered breathing and parasomnia. But it represents a simple bedside screening way for the detection of poststroke sleep disorders that would help physicians and healthcare personals who are engaged with stroke patients to better manage these disorders.

In conclusion, sleep and stroke have a definite relationship, sleep disorders are broadly prevailing after stroke, and resulting damage hinders the process of rehabilitation, and holds up neuronal plasticity and consequently impecunious functional outcome. Simple questionnaires are easy applicable methods for screening of such disorders post-stroke. Guidelines needed regarding screening and management of Sleep disorders after the stroke through further larger cohort studies.

\section{Supplementary information}

Supplementary information accompanies this paper at https://doi.org/10. 1186/s41983-020-0148-x

Additional file 1. The questionnaires.

\section{Abbreviations}

EDS: Excessive day time sleepiness; ESS: Epworth sleepiness scale; LC: Locus coeruleus; LDT: Lateral dorsal tegmentum; NIHSS: National Institute of Health Stroke Scale; PPD: Pedunculopontine nucleus

\section{Acknowledgements}

Not applicable.

\section{Authors' declaration}

- This is a thesis accepted by the local committee of Neurology Department, Faculty of Medicine at Ain Shams University in October 2014 and approved by Ain Shams University Committee in November 2014

- The article has not been published before and is not under simultaneous review by any other journal.

- Authors declare that there was no fund for this study and that there is no any conflict of interest.

- Consent has been signed by all patients before enrollment in the study

Authors' contributions

AM contributed to the conception and design of the idea, writing the first draft of the manuscript and collection of scientific material. MA contributed to the collection of data, writing the first draft of the manuscript and collection of scientific material. NE contributed to the revision of the manuscript and data analysis. AE shared in the collection of scientific 
material and analysis. TA contributed to the conception and design of the idea, scientific revision of the manuscript, and analyzed data. All authors read and approved the final manuscript.

\section{Funding}

Not applicable.

\section{Availability of data and materials}

Dataset is available as a master sheet in the archive library of Ain Shams University or via direct communication with the corresponding author.

\section{Consent for publication}

Not applicable.

\section{Competing interests}

The authors declare that they have no competing interests.

\section{Author details}

${ }^{1}$ Neurology Department, Faculty of Medicine, Ain Shams University, Ramsis St., Abbassis Square, Cairo, Egypt. ${ }^{2}$ Mataria Educational Hospital, Cairo, Egypt.

Received: 4 December 2019 Accepted: 6 January 2020 Published online: 17 January 2020

\section{References}

1. Groeneveld IF, Goossens PH, van Braak I, et al. Patients' outcome expectations and their fulfilment in multidisciplinary stroke rehabilitation. Ann Phys Rehabil Med. 2019;62:21-7.

2. Abd-Allah F, Khedr E, Oraby Ml, et al. Stroke burden in Egypt: data from five epidemiological studies. Int J Neurosci. 2018;128(8):765-71.

3. Mansour A, Kamel T, Asaad T, Metwally Y, et al. Clinical and polysomnographic study of RBD in Parkinson's disease from Egypt. Sleep Med. 2013;14(Suppl 1):e18.

4. Mansour A, Kamel T, Yaser M, Asaad T, et al. Clinical correlates of periodic limb movements in sleep in Parkinson's disease in Egypt. Sleep Med. 2013; 14(Suppl):e150.

5. Jean-François G, Postuma RB, Mazza S, Doyon J, et al. Jacques Montplaisir, Rapid-eye-movement sleep behaviour disorder and neurodegenerative diseases. Lancet Neurol. 2006;5:424-32.

6. Khot SP, Morgenstern LB. Sleep and stroke. Stroke J. 2019;50:1612-7.

7. Asaad T. Sleep Disorders' Scales. In: Asaad T, editor. Sleep: problems, diagnosis, and management. Cairo: Itrak. (Printed ); 2009. p. 117-49. (In Arabic Language).

8. Buysse DJ, Reynolds CF, Monk TH, Berman SR, Kupfer DJ. The Pittsburgh Sleep Quality Index: a new instrument for psychiatric practice and research. Psychiatry. 1989;28(2):193-213.

9. John MW. A new method for measuring sleeping. The Epworth sleepiness scale. Sleep. 1991;14(6):40-5.

10. Brott T, Adams HP Jr, Olinger CP, Marler JR, et al. Measurements of acute cerebral infarction: a clinical examination scale. Stroke. 1989;20(7):864-70.

11. Chokroverty S. Neurobiology of rapid eye movement and non-rapid eye movement sleep. In: Chokroverty S, editor. Sleep Disorders Medicine: Basic Science, Technical Considerations, and Clinical Aspects. Philadelphia: Saunders/Elsevier, Print; 2009. p. 29-58.

12. Ferrea A, Ribób M, Rodríguez-Lunab D, et al. Strokes and their relationship with sleep and sleep disorders. Neurología. 2013;28(2):103-18.

13. Friedman EM. Sleep Quality, Social wellbeing, gender and inflammation: an integrative analysis in a national sample. Ann NY Acad. 2011;1231(1):23-4.

14. Meier-Ewert HK, Ridkar PM, et al. Effect of sleep loss on C-reactive protein, an inflammatory marker of cardiovascular risk. J Am Co Cardiol. 2004;43(4): 678-83.

15. Shearer WT, Reuben JM, Mullington JM, et al. Soluble TNF-alpha receptor 1 and IL-6 plasma levels in humans subjected to the sleep deprivation model of space flight. J Allergy Clin Immunol. 2001;107(1):165-70.

16. ladecola C, Anthrather J. Stroke research at a crossroad: asking the brain for directions. Nat Neurosci. 2011;14(11):1363-8. https://doi.org/10. 1038/nn.2953.

17. Konsman JP, Drukarch B, Van Dam A-M. (Peri)vascular production and action of pro-inflammatory cytokines in brain pathology. Clin Sci (Lond). 2007;112(1):1-25.
18. Dussa SB, Seilera A, Schmidta MH, Paceb M, et al. The role of sleep in recovery following ischemic stroke: a review of human and animal data. Neurobiol Sleep Circadian Rhythms. 2017;2:94-105.

19. Bassetti CL. Sleep and stroke. Semin Neurol. 2005;25:19-32.

20. Bassetti CL, Milanova M, Gugger M. Sleep-disordered breathing and acute ischemic stroke diagnosis, risk factors, treatment, evolution, and long-term clinical outcome. Stroke. 2006:37:967-72.

21. Brown DL, Shafie-Khorassani F, Kim S, Chervin RD, et al. SleepDisordered Breathing Is Associated With Recurrent Ischemic Stroke. Stroke J. 2019;50:571-6.

22. Stevens D, Martins RT, Mukherjee S, Vakulin A. Post-stroke sleep-disordered breathing - pathophysiology and therapy options. 2018;26:5-9. https://doi. org/10.3389/fsurg.2018.00009.

23. Parra O, Arboix A, Bechich S, et al. Time course of sleep-related breathing disorders in first ever stroke or TIA. Am J Respi Crit Care Med. 2000;161(2 Pt 1):375-80.

24. Sandberg O, Franklin KA, Wang YM. Sleep Apnea, delirium, depressed mood, cognition and ADL ability after stroke. J Am Geriter Soc. 2001; 49:391-7.

25. Dziewas R, Hopmann B, Humpert M, et al. Positional sleep apnea in patients with ischemic stroke. Neurol Res. 2008;30:645-8.

26. Baylan S, Griffiths S, Grant N, Broomfield NM, Evans JJ, Gardani M. Incidence and prevalence of post-stroke insomnia: a systematic review and metaanalysis. Sleep Med Rev. 2020;49. https://doi.org/10.1016/j.smrv.2019.101222.

27. Hea Y, Gua M, Zhanga H, Denga J, et al. Effect of insomnia after acute ischemic stroke on cerebrovascular reactivity: a prospective clinical study in China. Sleep Medicine. 2019;63:82-7.

\section{Publisher's Note}

Springer Nature remains neutral with regard to jurisdictional claims in published maps and institutional affiliations.

\section{Submit your manuscript to a SpringerOpen ${ }^{\circ}$ journal and benefit from:}

- Convenient online submission

- Rigorous peer review

- Open access: articles freely available online

High visibility within the field

- Retaining the copyright to your article

Submit your next manuscript at $\boldsymbol{\nabla}$ springeropen.com 